\section{Ophthalmic injuries in British Armed Forces in Iraq and Afghanistan}

${ }^{1}$ Academic Department of Military Surgery and Trauma, Royal Centre for Defence Medicine, Birminghame, UK

${ }^{2}$ Birmingham and Midland Eye Centre, Birmingham, UK

Correspondence: RJ Blanch, Birmingham and Midland Eye Centre, Dudley Road, Birmingham, B18 7QH, UK Tel: + 44 (0)121554 3801 . E-mail: richard.blanch@ tiscali.co.uk

Received: 10 August 2010 Accepted in revised form: 26 October 2010;

Published online: 17

December 2010

Some of the data were presented as a poster at The Royal College of Ophthalmologists Annual Congress in May 2009

(Title 'Ocular Injuries in British Armed Forces in Iraq and Afghanistan' reference RCO200811151456 566022).

\section{Abstract}

Aim British military ophthalmologists have not been deployed in support of operations since 2003. Eye injuries in British forces receive definitive treatment on return to the United Kingdom. We report the injury patterns, management strategies, and outcomes for eye injuries in British Armed Forces in Iraq and Afghanistan.

Methods Retrospective consecutive case series of eye injuries in British Armed Forces in Iraq or Afghanistan from July 2004 to May 2008. Outcomes assessed by final best-corrected visual acuity (VA; few patients lost to follow-up), rates of endophthalmitis, and proliferative vitreoretinopathy (PVR). Results There were 630 cases of major trauma, 63 sustained eye injuries $(10 \%)$, and 48 sustained significant eye injuries. There were 21 open-globe injuries: 9 ruptures and perforating injuries, of which 7 were enucleated/eviscerated; 11 intraocular foreign body (IOFB) injuries, of which 1 was eviscerated. Primary repair was combined with posterior segment reconstruction in 9/11 cases with IOFB. Mean time to primary repair was 1.9 days (range $0-5$ ). Intravitreal antibiotics were given at primary repair in five cases. All cases received early broad-spectrum systemic antibiotics. Median final VA was logMAR 0.25 excluding evisceration/enucleations. There were two cases of PVR and none of endophthalmitis.

Conclusions The number of eye injuries as a proportion of all casualties is lower than recently reported. The injuries are more severe than in civilian practise. The outcomes were comparable with previous reports, this demonstrates that, in certain cases, primary repair can be safely delayed beyond $24 \mathrm{~h}$ in the patient's best interests, in order to optimise the conditions for treatment.
Eye (2011) 25, 218-223; doi:10.1038/eye.2010.190; published online 17 December 2010

Keywords: eye injuries; war; blast injuries; eye injuries, penetrating; vitrectomy

\section{Introduction}

British Armed Forces have been involved in combat operations in Iraq on Operation TELIC since March 2003 and in Helmand province, Afghanistan on Operation HERRICK since May 2006. In both theatres, they have faced threats throughout the spectrum of conflict from armoured manoeuvre warfare to counter insurgency.

British military ophthalmologists have not been deployed in support of operations since May 2003. Eye injuries requiring the input of an ophthalmologist in either theatre can be treated through two routes. All are evacuated back to the United Kingdom, and seen and treated in the Royal Centre for Defence Medicine (RCDM) in Birmingham; a minority are managed in-theatre and returned via United States facilities in Germany. The decision to evacuate most eye injuries to the United Kingdom ensures an optimal environment for treatment.

We aim to present data on all ocular trauma occurring in British Armed Forces in Iraq and Afghanistan between 19 July 2004 and 2 May 2008. We describe injuries sustained, management, and outcomes including delayed complications.

\section{Materials and methods}

This study was registered as an audit with University Hospitals Birmingham NHS trust. This is a retrospective, non-comparative interventional case series.

We included all cases of ocular trauma occurring in British military personnel who 
survived injuries (ocular or otherwise) severe enough to merit admission to hospital on return to the United Kingdom. Cases were identified using the United Kingdom Joint Theatre Trauma Registry (JTTR). In addition, cases that were missed by that database were identified by searching clinic letters for the keywords, 'Iraq,' 'Afghanistan,' 'TELIC,' 'HERRICK,' and 'Blast.' Patients who were treated in theatre by nonophthalmologists and returned to duty are not included.

Data were extracted from the patients' paper medical records and recorded on a Microsoft Excel spreadsheet for analysis. Where available, data collected included: demographic data; time and place of injury; actions at time of injury; personal protective equipment; all ocular and other injuries sustained with initial examination findings; initial, best and final visual acuity (VA); all operative interventions; medical interventions relevant to ocular management (ocular medications and systemic antibiotics); functional and occupational outcome.

We categorised injuries as open or closed in line with the Birmingham eye trauma terminology, ${ }^{1}$ as seen in Figure 1. To facilitate comparison with other studies that included only significant ocular injuries, ${ }^{2,3}$ we did not count subconjunctival haemorrhage, corneal abrasion, or superficial foreign bodies as significant injuries, and placed these in an additional minor injuries category. We could not distinguish between rupture and perforating injuries. In these cases the eye was severely disrupted and there were probable elements of each injury mechanism present. Adnexal injuries occurring in conjunction with globe injury were counted as one injury. None occurred in isolation.

Initial VA may be recorded in theatre by non-ophthalmologists, on arrival in the United Kingdom on ophthalmology assessment or on regaining consciousness in the critical care unit. We report outcomes by final VA either at 6-12 months after surgery

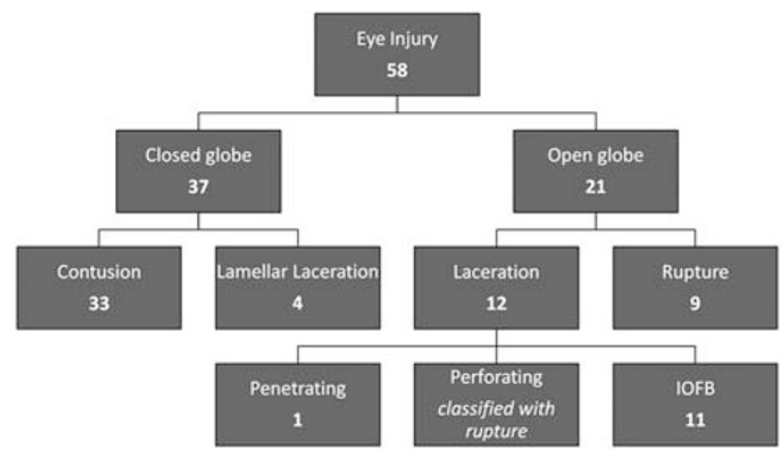

Figure 1 Number of injuries classified by the Birmingham Eye Trauma Terminology System. An additional 24 minor injuries are not shown here (subconjunctival haemorrhage, corneal abrasion, and superficial foreign body). or at discharge from follow-up. Final VA is a useful measure, because patients are rarely discharged or transferred to another centre before they are functionally stable and permanent occupational recommendations can be made.

For the purposes of analysis, Snellen VA measurements were converted to logMAR, including those with acuity $<1 / 60 .{ }^{4}$ Severity was assessed using the ocular trauma score (OTS), ${ }^{5}$ calculated retrospectively. Severity of open-globe injuries was assessed using classification and regression tree (CART) analysis. ${ }^{6}$

Our statistical analysis is descriptive, with average values given as the median in those cases in which the data is not numeric or does not appear to follow the normal distribution, and as the mean in other cases. We used Spearman's rank to calculate the correlation of final VA with OTS.

\section{Results}

A total of 630 British soldiers survived major traumatic injuries from 19 July 2004 to 2 May 2008. Of these, $63(10 \%)$ suffered ocular injuries affecting 82 eyes with 19 bilateral injuries $(30.2 \%)$. The ocular injuries were classed as significant in 58 eyes of 48 individuals, $7.6 \%$ of major injuries. Over the same time period, 7447 United Kingdom soldiers were wounded in action (WIA) with 492 ocular injuries (6.6\%). Because all major injuries were aeromedically evacuated from theatre, we can calculate that $48(0.64 \%)$ of those WIA suffered significant ocular injuries.

We were able to check the pre-injury VA in all cases, as all soldiers undergo visual screening on entry to the British Armed Forces and at regular intervals thereafter. Only one soldier had a history of ambylopia in the injured eye. Two injuries occurred in women-one minor and one closed. In all, $54.5 \%$ of all injuries were to the left eye and $44.5 \%$ to the right. The mean age at time of injury was 26.5 years (range 18-53). In all, 52\% of all injuries occurred in Iraq on Operation TELIC and $48 \%$ in Afghanistan on Operation HERRICK.

Explosive blast injuries occurred in $54 / 63$ patients $(86 \%)$; closed globe contusion injuries occurred in 6/63 $(9.5 \%)$ cases. There were three cases of disease non-battle injury; one following a motor vehicle collision, one from a non-combat-related aircraft incident and one associated with electrical burn. Among the significant injuries, 40/48 (83\%) were caused by explosive blast.

Mean follow-up for all closed globe injuries was 245 days and 220 days for open injuries. The first recorded VA was at a mean of 7.8 days after injury for closed injuries and 3.6 days for open injuries. Mean time from injury to arrival in the United Kingdom was 
2.63 days (median 1) for all injuries and 2.52 days for open injuries (median 1).

The distribution of injuries is shown in Figure 1. Of the 58 severe injuries, 22 ( $38 \%$ of eyes) had an associated adnexal injury, for example, lid lacerations, burns, or orbital fractures. Facial or orbital fractures occurred in 17 of 48 patients (35\%). Penetrating or closed brain injury with structural abnormality on imaging occurred in nine patients (19\%); cases of mild traumatic brain injury/ post-concussive syndrome were not included. Isolated eye injuries occurred in nine individuals (19\%), of which one was minor. A further seven cases (two minor) were associated with soft tissue fragmentation injuries, which required no treatment.

Of 21 open-globe injuries (Figure 1), 11 were associated with an IOFB - 1 of these penetrated the anterior segment only, 1 was intralenticular and 4 penetrated the eye posterior to the equator. A lens injury occurred in $6 / 11(54.5 \%)$ of IOFB injuries and $2(18.2 \%)$ were recorded to have associated retinal detachments.

For open-globe injuries, mean time to primary repair was 1.9 days (range $0-5$ ) with an average of 1.57 operations per eye. The procedures performed are summarised in Table 1. In all, 9/11 of the eyes with IOFB had vitrectomy and IOFB removal at the time of primary repair. Of the two other eyes, one had an anterior chamber IOFB and one had primary repair carried out in coalition facilities in Iraq followed by vitrectomy at 4 days in the United Kingdom and evisceration at 11 days.

Of the nine ruptured globes, seven $(77.8 \%)$ were ultimately enucleated or eviscerated (five as a primary procedure). A temporary keratoprosthesis was used during surgery in one case of rupture (OTS 1, initial VA light perception (LP), and final VA hand movements (HM) at 223 days); the final VA in the other ruptured globe injury was no LP.

Intravitreal antibiotics were given in 5/16 eyes at the time of primary repair (with vitrectomy). All open-globe injuries received broad-spectrum systemic antibiotics before evacuation and there were no cases of endophthalmitis. Of 12 open-globes repaired, 2 developed proliferative vitreoretinopathy (PVR) and retinal re-detachment. The distribution of closed injuries is summarised in Table 2. Surgery was required in 10/37 of these eyes with an average of 1.2 operations per eye; summarised in Table 1.

The correlation of final VA with the OTS for all injuries is shown in Table 3. The median OTS for closed-globe injuries was 4 , with a median final VA of $0.2(6 / 10)$. The median OTS for IOFB injuries was 2.5 , with a median final VA of $1.45(6 / 169)$; this improved to a median final VA of $0.25(6 / 11)$ when the two eviscerated eyes were excluded. Figure 2 shows the outcome of open-globe
Table 1 Summary of all surgical procedures performed. Of 11 intraocular foreign body injuries, primary repair was combined with posterior segment reconstruction in 9

\begin{tabular}{|c|c|c|}
\hline & Procedure & $\begin{array}{l}\text { Number } \\
\text { of cases }\end{array}$ \\
\hline \multirow{6}{*}{$\begin{array}{l}\text { Primary procedures } \\
\text { on open-globe injuries }\end{array}$} & Primary repair only & 7 \\
\hline & $\begin{array}{l}\text { Primary repair/vitrectomy/ } \\
\text { gas tamponade }\end{array}$ & 2 \\
\hline & $\begin{array}{l}\text { Primary repair/vitrectomy/ } \\
\text { silicone oil tamponade }\end{array}$ & 3 \\
\hline & Primary repair/vitrectomy & 4 \\
\hline & Enucleation & 4 \\
\hline & Evisceration & 1 \\
\hline \multirow[t]{9}{*}{$\begin{array}{l}\text { Secondary procedures } \\
\text { on open-globe injuries }\end{array}$} & $\begin{array}{l}\text { Penetrating keratoplasty/ } \\
\text { Morcher lens insertion }\end{array}$ & 1 \\
\hline & $\begin{array}{l}\text { Vitrectomy/encirclage/ } \\
\text { silicone oil tamponade }\end{array}$ & 1 \\
\hline & $\begin{array}{l}\text { Vitrectomy/keratoprosthesis/ } \\
\text { silicone oil tamponade }\end{array}$ & 1 \\
\hline & $\begin{array}{l}\text { Vitrectomy/silicone oil } \\
\text { tamponade }\end{array}$ & 2 \\
\hline & $\begin{array}{l}\text { Phacoemulsification/ } \\
\text { removal of silicone oil }\end{array}$ & 1 \\
\hline & Lens insertion & 1 \\
\hline & Orbital floor implant & 1 \\
\hline & Enucleation & 2 \\
\hline & Evisceration & 2 \\
\hline \multirow[t]{10}{*}{$\begin{array}{l}\text { All procedures on } \\
\text { closed-globe injuries }\end{array}$} & $\begin{array}{l}\text { Examination under } \\
\text { anaesthesia }\end{array}$ & 4 \\
\hline & Ectropion/entropion repair & 2 \\
\hline & $\begin{array}{l}\text { Lens aspiration/intraocular } \\
\text { lens insertion }\end{array}$ & 3 \\
\hline & Anterior vitrectomy & 2 \\
\hline & Posterior capsulotomy & 1 \\
\hline & $\begin{array}{l}\text { Gray line split/lamellar } \\
\text { repositioning/skin graft }\end{array}$ & 1 \\
\hline & Strabismus surgery & 1 \\
\hline & Vitreolensectomy & 1 \\
\hline & Intraocular lens insertion & 1 \\
\hline & Indirect laser retinopexy & 1 \\
\hline
\end{tabular}

injuries divided by the CART analysis and correlated to previous reports. Sensitivity and specificity for OTS and CART were calculated for open-globe injuries as previously described. ${ }^{7}$ McNemar $\chi^{2}$-test was used to compare sensitivity and specificity measures of CART and OTS, as previously described. ${ }^{8} P$-values were $>0.05$ for all comparisons.

Of 34 eyes with initial $\mathrm{VA} \leq 6 / 60,18$ had final $\mathrm{VA}<6 / 60$. A total of 17 eyes had a final VA of $1 / 60$ or worse, of which 6 (3 patients) were bilateral. The causes were: rupture/extensive disruption (nine eyes), corneal scar (two eyes), PVR (two eyes), traumatic optic neuropathy (one eye), subfoveal choroidal rupture (one eye), IOFB impacted fovea (one eye), retinal burns from hot IOFB (one eye). 
Table 2 Closed-globe injuries

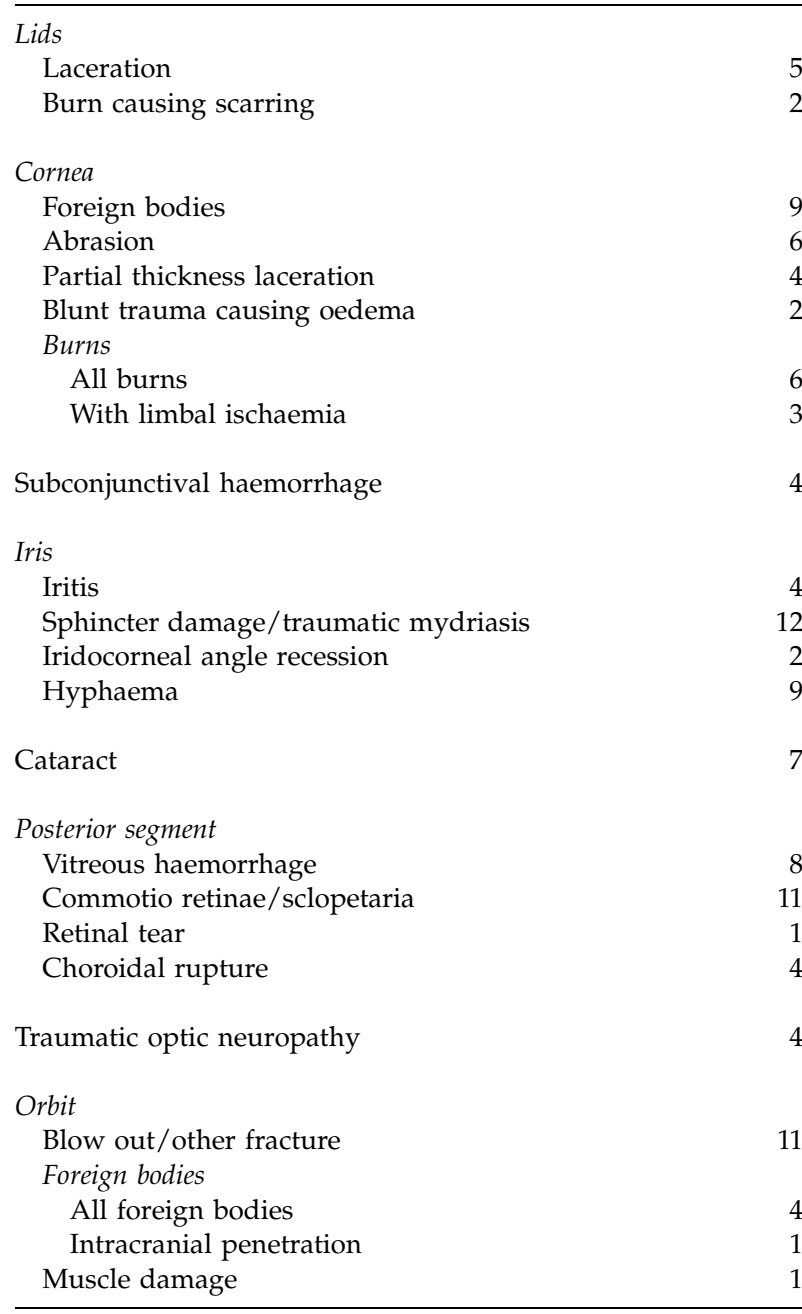

Eyes with minor injuries only excluded. A total of 37 eyes.

Table 3 Correlation of final visual acuity with OTS

\begin{tabular}{lcccccc}
\hline $\begin{array}{l}\text { No. of } \\
\text { points }\end{array}$ & OTS & $\begin{array}{c}\text { NLP } \\
(\%)\end{array}$ & $\begin{array}{c}L P / H M \\
(\%)\end{array}$ & $\begin{array}{c}C F \leq 6 / 60 \\
(\%)\end{array}$ & $\begin{array}{c}6 / 60 \leq 6 / 12 \\
(\%)\end{array}$ & $\begin{array}{c}\geq 6 / 12 \\
(\%)\end{array}$ \\
\hline $0-44$ & 1 & 83 & 17 & & & \\
$45-65$ & 2 & 33 & 17 & 17 & 17 & 17 \\
$66-80$ & 3 & 7.1 & 14 & 14 & 21 & 43 \\
$81-91$ & 4 & & & & 30 & 70 \\
$>92$ & 5 & & & & 6.9 & 93 \\
\hline
\end{tabular}

Abbreviations: $\mathrm{CF}$, counting fingers; HM, hand movement; LP, light perception; NLP, no light perception; OTS, ocular trauma score.

Percentages to two significant figures. Total number 65 , on whom OTS could be calculated. Spearman's rank correlation coefficient $(\mathrm{df}=63$ two-tailed, tied rank corrected) $=-0.730 P<0.0001$. For 15 open-globe injuries on which OTS could be calculated Spearman's rank correlation coefficient $(\mathrm{df}=13$, two- tailed, tied rank corrected $)=-0.137 P>0.05$. Sensitivity to predict visual survival (see Figure 2) is $75 \%$, specificity to predict visual loss is $71 \%$. Sensitivity to predict minimal to severe visual loss (see Figure 2) is $75 \%$, specificity to predict profound visual loss is $82 \%$.
Eye protection was recorded as worn in 7/63 patients. Of these, one had an IOFB injury with hot metal, ultimately requiring evisceration, and one had a closed-globe injury with an orbital foreign body (vision recovered to 6/18), the remainder were minor injuries. Of those not recorded as wearing eye protection, 11/56 had a final VA of HM or worse (including enucleation/ evisceration), compared to $1 / 7$ where protection had been worn.

\section{6}

This is a complete report of all United Kindgom military ocular injuries from Iraq and Afghanistan, as there is a single point of treatment delivery and follow-up that allows comprehensive data to be collected. This allows long-term outcomes to be recorded, unlike other reports of military trauma. Common to other military trauma reports there were difficulties recording the initial VA and assessment of patients due to comorbidities. ${ }^{9}$ The data recorded appeared broadly to conform to OTS and CART predictions though the delay in data collection might have made the scoring systems less reliable.

Military ocular injuries cannot be directly compared with the experience of civilian trauma. The vast majority of military patients are male $(98 \%)$ compared with $80 \%$ of civilians. High energy explosive blast injuries are sustained in $83 \%$ compared with $3 \%$ in civilians. ${ }^{9}$ Military injuries cause greater ocular damage, with an initial VA of $\leq 6 / 60$ recorded in $71 \%$ compared with $27 \%$ among civilians. ${ }^{10}$ Military ocular injuries are associated with severe polytrauma in $75 \%$ of cases (source United Kingdom JTTR); this is rare in the civilian setting.

The total number of ocular casualties is much lower than that reported in the United States military $2,3,9,11$ reflecting differences in the overall number of casualties between the British and the United States Armed Forces. It is difficult to compare the proportion of eye injuries between different reports, as there are subtle differences in how the data are presented. In our series $6.6 \%$ of WIA suffered ocular injuries, though only $0.64 \%$ suffered significant ocular injury. This is in line with historical data $^{12}$ but much less than the $4.9 \%$ of WIA suffering 'severe' ocular injury reported by Thach et al. ${ }^{2}$ Mader et $a l^{3}$ reported $10 \%$ of surgical admissions with 'severe' eye injuries, similar to the $7.6 \%$ of major trauma in our series. Though both studies defined 'severe' differently, they were broadly similar to our definition of significant injury.

We report a high proportion of blast injuries (86\%) compared with a figure of $70-80 \%$ in previous reports. ${ }^{12}$ Our figures are not representative of the United Kingdom JTTR as a whole, who in the same period had 


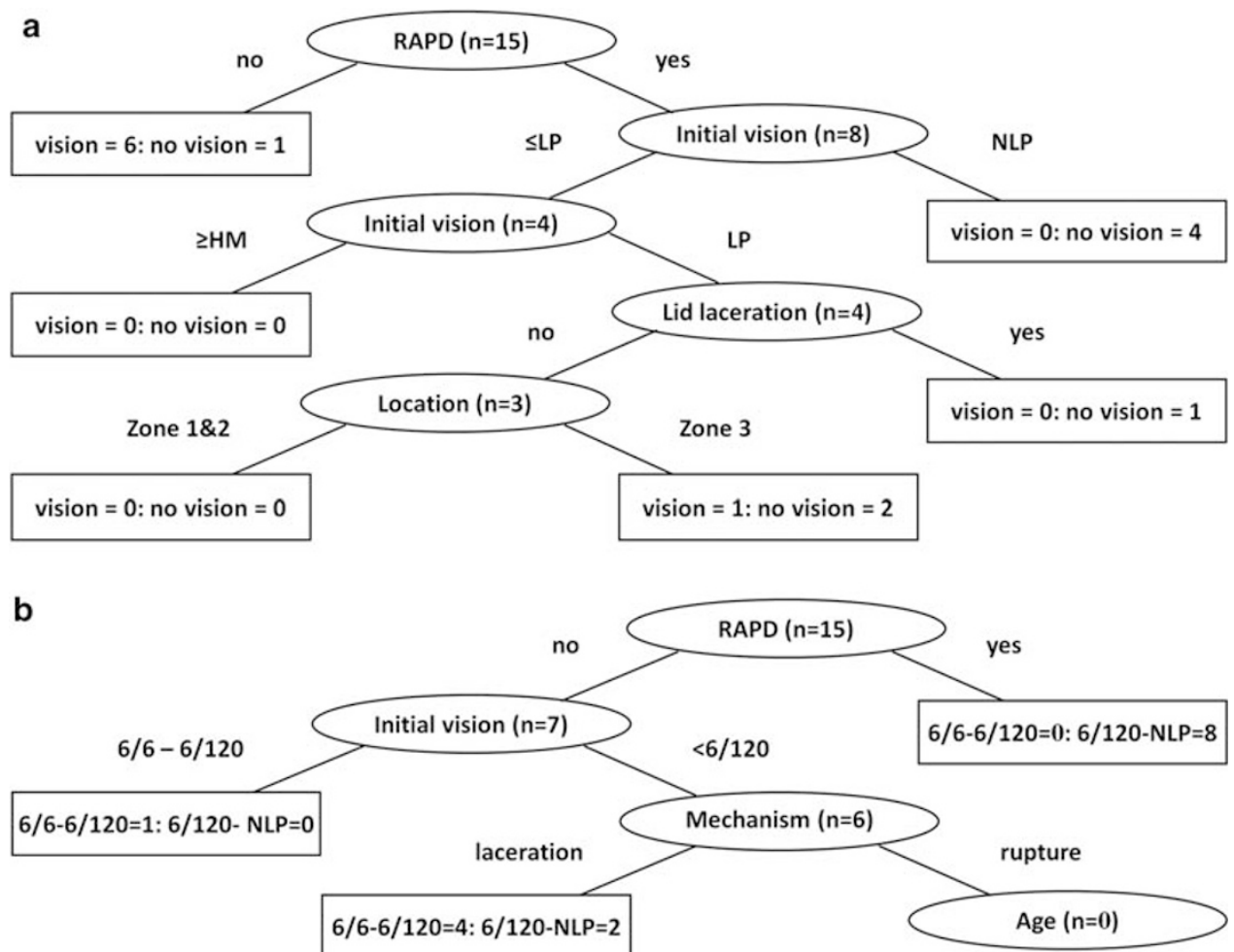

Figure 2 Outcomes displayed by the classification and regression tree (CART) analysis. (a) Visual survival ( $\geq$ LP) vs no vision (NLP). Sufficient data was available on 15 open-globe injuries. Sensitivity to predict visual survival is $86 \%$, specificity to predict no vision is $87.5 \%$. (b) Minimal to severe vs profound visual loss. Sufficient data was available on 15 open-globe injuries. Sensitivity to predict minimal to severe loss is $100 \%$, specificity to predict profound loss is $80 \%$. RAPD, relative afferent pupillary defect; HM, hand movements; LP, light perception; NLP, no light perception.

$57 \%$ blast injuries (source United Kingdom JTTR). It is possible that other causes of major trauma - gunshot wound, motor vehicle incidents, and non-battle injury, are less likely to involve the eyes compared with improvised explosive devices targeted at the face. The enforced use of safety devices in-theatre, such as seatbelts and eye protection, probably reduces the incidence of eye injuries.

Our practise differs from other reports in that we delay primary repair until optimal facilities are available and combine it with posterior segment reconstruction. For open-globe injuries, our average final VA compares well with other series of military IOFB injuries. Bajaire et $a l^{13}$ report final VA $>20 / 800$ in only $39 \%$ in a Columbian case series of military open-globe injuries. Sobaci et al ${ }^{14}$ report VA $>5 / 200$ at 6 months in only $47 \%$. Colyer et $a l^{11}$ present a more comparable series of United States military IOFB injuries with a mean VA at 6 months of logMAR 0.43 (6/16 Snellen) excluding enucleations and eviscerations compared to our median final VA of logMAR 0.25 (6/11 Snellen). It was 1.45 (6/169 Snellen) with these included. Early posterior segment reconstruction is currently the subject of a multi-centre prospective study. ${ }^{15}$ We report a low rate of PVR (15\%) - compared with $>20 \%$ in other comparable series. ${ }^{11,13,14}$ We promote the use of systemic antibiotics with open-globe injuries and had no cases of endophthalmitis; the rate in comparable reports varies from 0 (Colyer et $a l^{11}$ ) to $8 \%$ (Sobaci et $a l^{14}$ ).

We aeromedically evacuate our eye injuries to the United Kingdom, with a mean time to primary repair of 1.9 days, significantly in excess of standard civilian practise $(<24 \mathrm{~h})^{16,17}$ and that reported by the United States military (within hours of injury). ${ }^{11}$ The delay allows soldiers to be evacuated to an ideal environment for treatment in a major teaching hospital environment with a full range of equipment and appropriately experienced staff. Our outcomes support the efficacy of this approach.

For our data as a whole, OTS seems to predict outcome well for scores of 1, 4, and 5 with less concordance with scores of 2 and 3 . Our outcomes are broadly in line with those originally reported by Kuhn et $a l^{5}$ and more recently by Weichel et $a l^{9}$ in a large military case series. For open-globe injuries specifically both CART and OTS predict outcomes less well than reported by 
Man and Steel, ${ }^{7}$ with a non-significant difference in favour of CART.

All soldiers are issued with polycarbonate spectacles and goggles for eye protection (Eye Safety Systems, Sun Valley, ID, USA), but a low proportion were documented as wearing it at the time of injury. We do not have data on the proportion of soldiers using eye protection in theatre and so cannot relate this to the efficacy of eye protection. A recent study found reduced eye injury rates from $26 \%$ of those without eye protection to $17 \%$ among those using it. $^{18}$

We managed the challenge of providing highly technical eye care to service personnel in two theatresof-war. This has been through good teamwork with the deployed hospitals and the aeromedical evacuation services. This study allows us to evaluate our outcomes to justify and develop our practise and to improve the treatment of our injured soldiers.

\section{Summary}

\section{What was known before}

- Delay to primary repair beyond $24 \mathrm{~h}$ increases the risk of endophthalmitis. Delay to intra-ocular foreign body removal is safe under antibiotic cover

\section{What this study adds}

- Primary repair can be safely delayed beyond $24 \mathrm{~h}$ in the patient's best interests in cases in which this allows optimal treatment.

\section{Conflict of interest}

The authors declare no conflict of interest.

\section{Acknowledgements}

We thank the Academic Department of Military Emergency Medicine for identifying some of the cases included in this paper.

\section{References}

1 Pieramici DJ, Sternberg Jr P, Aaberg Sr TM, Bridges Jr WZ, Capone Jr A, Cardillo JA et al. A system for classifying mechanical injuries of the eye (globe). The Ocular Trauma Classification Group. Am J Ophthalmol 1997; 123(6): 820-831.

2 Thach AB, Johnson AJ, Carroll RB, Huchun A, Ainbinder DJ, Stutzman RD et al. Severe eye injuries in the war in Iraq, 2003-2005. Ophthalmology 2008; 115(2): 377-382.
3 Mader TH, Carroll RD, Slade CS, George RK, Ritchey JP, Neville SP et al. Ocular war injuries of the Iraqi Insurgency, January-September 2004. Ophthalmology 2006; 113(1): 97-104.

4 Johnson GJ, Minassian DC, Weale R, West SK. The Epidemiology of Eye Disease. Arnold: London, UK, 2003.

5 Kuhn F, Maisiak R, Mann L, Mester V, Morris R, Witherspoon CD et al. The ocular trauma score (OTS). Ophthalmol Clin N Am 2002; 15(2): 163-165.

6 Schmidt GW, Broman AT, Hindman HB, Grant MP. Vision survival after open globe injury predicted by classification and regression tree analysis. Ophthalmology 2008; 115(1): 202-209.

7 Man CY, Steel D. Visual outcome after open globe injury: a comparison of two prognostic models - the ocular trauma score and the classification and regression tree. Eye 2009; 24(1): 84-89.

8 Trajman A, Luiz RR. McNemar x2 test revisited: comparing sensitivity and specificity of diagnostic examinations. Scan J Clin Lab Invest 2008; 68(1): 77-80.

9 Weichel ED, Colyer MH, Ludlow SE, Bower KS, Eiseman AS. Combat ocular trauma visual outcomes during operations Iraqi and Enduring Freedom. Ophthalmology 2008; 115(12): 2235-2245.

10 Kuhn F, Morris R, Witherspoon CD, Mann LR. Epidemiology of blinding trauma in the United States eye injury registry. Ophthalmic Epidemiol 2006; 13(3): 209-216.

11 Colyer MH, Chun DW, Bower KS, Dick JS, Weichel ED. Perforating globe injuries during operation Iraqi freedom. Ophthalmology 2008; 115(11): 2087-2093.

12 Wong TY, Seet MB, Ang CL. Eye injuries in twentieth century warfare: a historical perspective. Surv Ophthalmol 1997; 41(6): 433-459.

13 Bajaire B, Oudovitchenko E, Morales E. Vitreoretinal surgery of the posterior segment for explosive trauma in terrorist warfare. Graefe's Arch Clin Exp Ophthalmol 2006; 244(8): 991-995.

14 Sobaci G, Akyn T, Mutlu FM, Karagül S, Bayraktar MZ. Terror-related open-globe injuries: a 10-year review. Am J Ophthalmol 2005; 139(5): 937-939.

15 Schrader WF, Pröll D, Mann L, Kuhn F. Prophylaxis of proliferative vitreoretinopathy by early vitrectomy in severe ocular trauma: preliminary results of a multicenter prospective study. International Society of Ocular Trauma and the German Retinal Society, Würzburg, Germany, 2008.

16 Thompson WS, Rubsamen PE, Flynn Jr HW, Schiffman J, Cousins SW. Endophthalmitis after penetrating trauma. Risk factors and visual acuity outcomes. Ophthalmology 1995; 102(11): 1696.

17 Thompson JT, Parver LM, Enger CL, Mieler WF, Liggett PE. Infectious endophthalmitis after penetrating injuries with retained intraocular foreign bodies. National eye trauma system. Ophthalmology 1993; 100(10): 1468.

18 Thomas R, McManus JG, Johnson A, Mayer P, Wade C, Holcomb JB et al. Ocular injury reduction from ocular protection use in current combat operations. J Trauma 2009; 66(4): S99. 